American Journal of Applied Sciences 7 (8): 1066-1072, 2010

ISSN 1546-9239

(C) 2010 Science Publications

\title{
Evaluation of Salivary Electrolytes during Normal Menstrual Cycle with Special Reference to Ovulation
}

\author{
${ }^{1,2} \mathrm{~S}$. Alagendran, ${ }^{1}$ Govindaraju Archunan, \\ ${ }^{2}$ Enrique Orozco Bonnila Armando and ${ }^{2}$ Rosalinda Guevara Guzman \\ ${ }^{1}$ Department of Animal Science, Centre of Pheromone Technology, \\ School of Life Sciences, Bharathidasan University, Tiruchirappalli-24, Tamil Nadu, India \\ ${ }^{2}$ Neuro Sensory Physiology Laboratory, Department of Physiology, \\ Faculty of Medicine, UNAM, Ave. Universidad CP-04510, Mexico DF
}

\begin{abstract}
There is evidence to imply that estrogen influences salivary electrolytes activity in women. Problem statement: In this study we investigated changes in sodium, potassium and inorganic phosphorus, calcium and magnesium which related to find out the precise day of ovulation. These changes might help to explain the fluctuation of ovarian hormones such as preovulatory estrogen surge. Approach: Human whole saliva was collected from 48 healthy subjects of women (age range 20-30 years) during reproductive phases of menstrual cycle were assayed using atomic absorption spectrometer and enzyme immune assay. Amongst a range of electrolytes have been identified such as sodium, potassium, inorganic phosphorus and calcium were comparatively found to be higher during ovulatory phase when compared to that of other phases. Changes were attributed to a probable hormonal outcome on salivary composition. Results: Conversely, in other phases (preovulatory and postovulatory) electrolytes activity like magnesium and calcium decreased later, declining significantly $(\mathrm{p}<0.05)$. The increase of electrolytes like sodium and potassium in human saliva, during ovulatory phase might be due to the circulation of steroid hormones. Conclusion: Further, the presence of particular salts influence by ovarian hormones like LH and progesterone in ovulatory saliva makes the possibility to expand a sign for spotlight of ovulation by means of noninvasive method.
\end{abstract}

Key words: Saliva, electrolytes, menstrual cycle, noninvasive method

\section{INTRODUCTION}

There is an increasing demand for cheap self tests to predict the fertile period in each menstrual cycle. A variety of endogenous biochemical substances have been found to fluctuate during the periovulatory period of the menstrual cycle; salivary electrolytes like sodium, potassium, magnesium, calcium, total phosphate as well as urea. Little work has been done on electrolytes. The cyclic physiologic changes are mainly brought about by the ovarian hormones; estrogen and progesterone the levels of which show variation during menstrual cycle. Identification of the period of ovulation in human is critical in the treatment of infertility. Success in vitro fertilization and embryo transfer has been associated with the exact time of ovulation. Recent year's attention has been paid on the non-invasive method in ovulation detection using saliva. Up to date, a variety of small hand-held microscopes have been developed and marketed for the purpose of self-observing ferning patterns in saliva. Theoretically, the ferning (crystallization) pattern of saliva coincides with the female fertile period. The ferning is caused by $\mathrm{NaCl}$, which cyclically increases under the influence of estrogen (Alagendran et al., 2007). Salivary ferning may be used as a new parameter to aid women to detect their fertile period.

Recent report shows that saliva was a very good source of both hormones and biochemical's and their levels changes in accordance with the menstrual cycle. Effect of ovarian hormones on water and electrolyte balance is well documented ands has been published earlier by Dadlani et al. (1982). Estrogen leads to a marked acceleration of calcium up take and decrease of its elimination through pigeon's gut (Silberberg and Silberberg, 1956). In non-pregnant women estrogen administration produces increased parathyroid activity (Pitkin et al., 1978). It is known that the calcium 
homeostasis is maintained by parathyroid glands. However, effect of menstrual cycle on serum calcium remains controversial (Pandya et al., 1995). It is also specific role to magnesium in regulation of menstrual function, although magnesium is involved in basal metabolism that changes over the course of menstrual cycle (Patricia, 1987). This evidence suggests possibly ovarian hormones influence calcium, magnesium, sodium, potassium and inorganic phosphate metabolism during different phases of menstrual cycle. During the part of the cycle between ovulation and the onset of menstruation (postovulatory phase), the concentration of progesterone is high. Progesterone reportedly has a natriuretic effect (Landau and Lugibihl, 1958) and the increase in progesterone after ovulation is thought to be followed by a compensatory rise in aldosterone concentration. Research concerning estradiol has focused predominantly on reproductive issues such as conception, ovulation, infertility and menopause (Lipson and Ellison, 1996). Nevertheless, estradiol affects a diversity of biological processes involved with pubertal and reproductive capacity, establishment and maintenance of pregnancy, infant care, coronary artery disease, immunocompetence and cancer susceptibility (Lipson and Ellison, 1996). Estradiol and other hormones like cortical and progesterone in addition assumed to affect individual differences in cognitive and socioemotional processes as well as psychopathology (Dorn et al., 2007; Shirtcliff et al., 2001). Salivary estradiol levels are unaffected by salivary flow rate or salivary enzymes. Unbound serum estradiol enters the saliva via intracellular mechanisms and in saliva the majority of estradiol remains unbound to protein (Lipson and Ellison, 1996; Loewit et al., 1987; Vining and McGinley, 1987).

The purpose of this study is to evaluate changes in salivary calcium, magnesium, sodium, potassium and inorganic phosphate and certain hormones like LH, cortical, estrogen and progesterone in health menstruating women. Thus, the presence of salivary specific electrolytes in ovulatory saliva makes the possibility to develop a biomarker for detection of ovulation by noninvasive methods.

\section{MATERIALS AND METHODS}

Forty eight normally menstruating women, around 20-30 years of age, participated as subjects in this serial study. The subjects were selected on the basis of normal and regular menstrual cycle ( $28 \pm 2$ days cycle). The saliva sample was taken from each subject during preovulatory, ovulatory and postovulatory phases. The volunteers were instructed to abstain from eating, smoking and drinking $10 \mathrm{~h}$ prior to testing. And also the volunteers were asked for tooth brushing to prevent minimal gingival bleeding.

The determination of different phases and the procedures of collection of saliva during these phases have been explained earlier in serum (Dadlani et al., 1982). In brief $5 \mathrm{~mL}$ of saliva was collected during 8.00-9.00 A.M in each phase. The saliva sample were centrifuged was $5000 \mathrm{rpm}$ at $4^{\circ} \mathrm{C}$ for $10 \mathrm{~min}$. The clear fluid was concentrated and used for the electrolyte testing in triplicate manner (Navazesh, 1993). Period of ovulation was judged by daily oral body temperature recordings, ferning pattern and determination of salivary calcium, magnesium, sodium, potassium and inorganic phosphate concentration was carried out on the same day collection by standard methods. Hormone assay like Luteinizing hormone, cortical, estrogen and progesterone was also done to hypothesize the ovualtory period using enzyme immunoassay kit method (Salimatrics, State College, PA, USA)

Biochemical assay: From the standard profile, the electrolyte concentration of unknown sample was identified and quantified by the method of Determination of calcium (Baron and Bell, 1959), Magnesium Determination in human saliva (Neill and Neely, 1956), Determination of salivary sodium (Gowenlock, 1988), Determination of Salivary Potassium, Inorganic phosphorus in human saliva (Voda et al., 1980). All the experiment was done in Perkin-Elmer Atomic Absorption Spectrophotometer Model 303, Norwalk, USA. Statistical analysis was done by one way ANOVA. Level of significance was pvalue of $0.05 \%$.

Hormone assay: Salivary hormone assay like LH, Progesterone, 17- $\beta$-Estradiol and Cortisol was analyzed in all three phases of menstrual cycle in relate to detect the exact time of ovulation. The intra-assay and interassay coefficients of variation were detected according to Salimatrics salivary hormone analysis kit model system (Salimatrics, State College, PA, USA).

Statistical analysis was done by one way ANOVA. Level of significance was p-value of $0.05 \%$ in $\mathrm{LH}$ and progesterone; NS in estradiol and cortical in all phases of menstrual cycle. In prepubertal and menopause saliva samples hormone values shows distinctive.

\section{RESULTS}

Saliva in human beings is produced mainly in the parotid, sublingual and submaxillary glands. Saliva samples are easy to obtain without pain and can be obtained on a daily basis (Hofman, 2001). 
Am. J. Applied Sci., 7 (8): 1066-1072, 2010

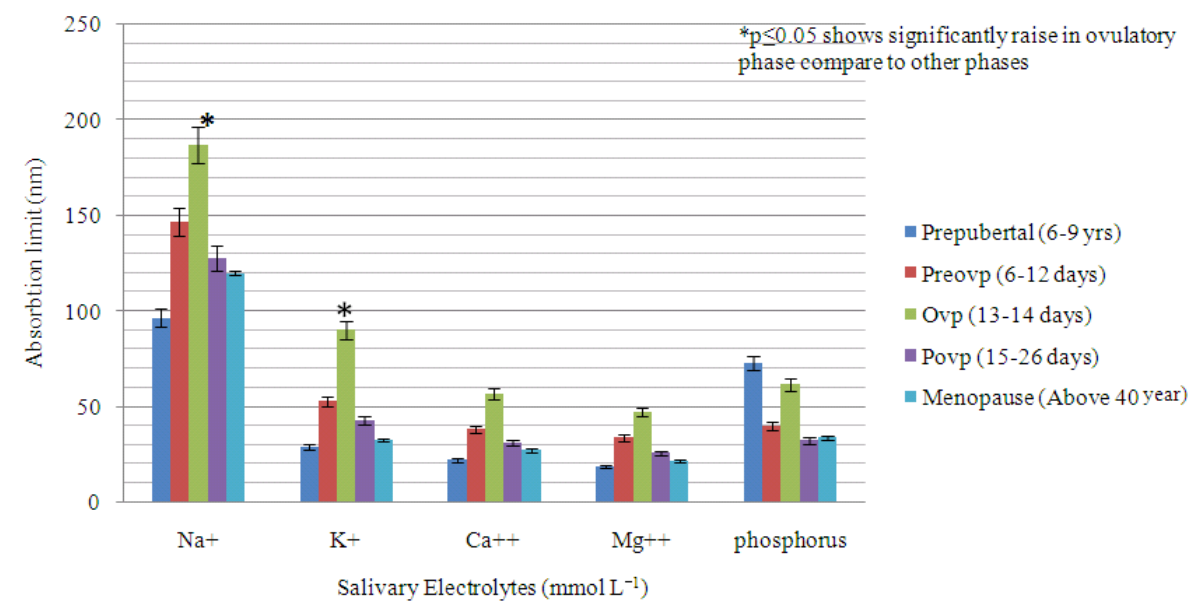

Fig. 1: The salivary electrolytes concentration during menstrual cycle

Table 1: Salivary electrolyte assay in normal menstrual cycle

\begin{tabular}{|c|c|c|c|c|c|}
\hline \multirow[b]{2}{*}{ Parameter } & \multicolumn{5}{|l|}{ Electrolytes } \\
\hline & $\begin{array}{l}\text { Prepubertal } \\
\text { (6-9 years) }\end{array}$ & $\begin{array}{l}\text { Preovulatory } \\
\text { phase (6-12 days) }\end{array}$ & $\begin{array}{l}\text { Ovulatory } \\
\text { phase (13-14 days) }\end{array}$ & $\begin{array}{l}\text { Postovulatory } \\
\text { phase (15-26 days) }\end{array}$ & $\begin{array}{l}\text { Menopause } \\
\text { (Above } 45 \text { years) }\end{array}$ \\
\hline Sodium $(\mathrm{Na}+)\left(\mathrm{mmol} \mathrm{L}^{-1}\right)$ & $96.17 \pm 22.56$ & $146.83 \pm 21.52$ & $186.78 \pm 25.77^{*}$ & $127.44 \pm 20.73$ & $119.72 \pm 25.46$ \\
\hline Potassium $(\mathrm{k}+)\left(\mathrm{mmol} \mathrm{L}^{-1}\right)$ & $28.76 \pm 6.240$ & $52.61 \pm 4.620$ & $89.81 \pm 8.900 *$ & $42.58 \pm 7.820$ & $32.59 \pm 6.670$ \\
\hline Calcium $(\mathrm{Ca}++)\left(\mathrm{mmol} \mathrm{L}^{-1}\right)$ & $21.66 \pm 3.680$ & $38.27 \pm 4.740$ & $56.62 \pm 5.010$ & $31.11 \pm 4.060$ & $26.84 \pm 4.710$ \\
\hline Magnesium $(\mathrm{mg}++)\left(\mathrm{mmol} \mathrm{L}^{-1}\right)$ & $18.51 \pm 3.220$ & $33.41 \pm 4.500$ & $47.09 \pm 5.240$ & $25.67 \pm 3.350$ & $21.56 \pm 3.390$ \\
\hline In organic Phosphorus $\left(\mathrm{mmol} \mathrm{L}^{-1}\right)$ & $27.68 \pm 3.440$ & $39.85 \pm 5.500$ & $61.48 \pm 9.270$ & $32.06 \pm 4.680$ & $33.81 \pm 4.520$ \\
\hline
\end{tabular}

*: Values are expressed as Mean \pm SE. Statistical analysis was done by one way ANOVA followed by Posthoc Tukey test for comparison between reproductive phases. Level of significance specify p-value of $0.05 \%$ in Sodium, potassium and phosphorus; NS in magnesium, calcium in all phases of menstrual cycle

It is known that saliva ferning depends principally on the electrolytes concentration (especially $\mathrm{NaCl}$ ) and chemo-physical properties of the mucins it contains (sialic acid) (Alagendran et al., 2007; 2009; Pattanasuttinont et al., 2007). The estrogens increase the water content in mid-cycle and determine the most favorable condition, optimal proportion of water and optimal amounts of salts and sialomucin (Oster and Yang, 1972). It was claimed that there were many advantages of salivary ferning test such as its high accuracy, low cost, convenience, re-usable and easy to use. Second, the average fall in the basal body temperature at the time of ovulation was $0.5^{\circ} \mathrm{F}(0.4-$ $0.7^{\circ} \mathrm{F}$ ). During the luteal phase, the temperature rose by $0.7-0.9^{\circ} \mathrm{F}$.

Salivary electrolytes like calcium, magnesium, sodium, potassium and inorganic phosphate levels during various phases of menstrual cycle are represented graphically in Fig. 1. Gradual increase in salivary sodium level $(\mathrm{F}=2.435,186.78 \pm 25.77)$ was seen from ovulatory phase $(\mathrm{p} \leq 0.05)$ and then to preovulatory phase $(p \leq 0.05)$ as compared to postovulatory phase. The mean salivary sodium, potassium and phosphorus levels of ovulatory phase was significantly $(\mathrm{p} \leq 0.05)$ higher than in other two phases. Magnesium and calcium gradually decrease from preovulatory to ovulatory phases and postovulatory phase to ovulatory phase $(\mathrm{p} \leq 0.05)$. Therefore it rises to its maximum in ovulatory periods (Table 1).

There is a cyclic variation in inorganic phosphorus level during the menstrual cycle. The highest level was seen during ovulatory phase $(\mathrm{p} \leq 0.05)$ compared to all other phases. During ovulatory periods sodium, potassium and inorganic phosphate increased significantly at $(p \leq 0.05)$ compared to preovulatory phases. The magnesium level is lowest $(p \leq 0.05)$ in postovulatory phase compared to all other phases of the menstrual cycle. However, none of the values was outside the normal range. Further, the analysis of electrolytes and hormones in saliva was followed ANOVA with the help of the SPSS version of statistical software.

Table 2 represent the salivary hormone vary in reproductive phases. The results suggest that unconjugated steroids enter saliva by diffusing through the cells of the salivary glands and that their concentration in saliva does not depend on the rate of saliva production. 
Am. J. Applied Sci., 7 (8): 1066-1072, 2010

Table 2: Salivary hormone assay in normal menstrual cycle using enzyme immune assay system

\begin{tabular}{|c|c|c|c|c|}
\hline $\begin{array}{l}\text { Salivary hormone } \\
\text { assay using EIA }\end{array}$ & $\begin{array}{l}\text { Preovulatory phase } \\
\text { (6-12 days) }\end{array}$ & $\begin{array}{l}\text { Ovulatory phase } \\
\text { (13-14 days) }\end{array}$ & $\begin{array}{l}\text { Postovulatory phase } \\
\text { (15-26 days) }\end{array}$ & $\begin{array}{l}\text { Coefficient } \\
\text { variation }(\%)\end{array}$ \\
\hline LH $\left(\mathrm{mIU} \mathrm{L}^{-1}\right)$ & $45.78 \pm 12.85$ & $96.54 \pm 28.65$ & $56.89 \pm 15.87$ & 0.857 \\
\hline Cortisol $\left(\mathrm{nmol} \mathrm{L}^{-1}\right)$ & $0.56 \pm 0.32$ & $1.45 \pm 0.980$ & $0.76 \pm 0.430$ & 1.810 \\
\hline 17 - $\beta$-estradiol $\left(\mathrm{pg} \mathrm{m} \mathrm{L}^{-1}\right)$ & $1.56 \pm 0.78$ & $3.22 \pm 1.650$ & $2.12 \pm 0.950$ & 1.400 \\
\hline Progesterone $\left(\mathrm{ng} \mathrm{m} \mathrm{L} \mathrm{L}^{-1}\right)$ & $76.4 \pm 23.87$ & $98.6 \pm 32.870$ & $123.7 \pm 56.980$ & 1.100 \\
\hline
\end{tabular}

Statistical analysis was done by one way ANOVA followed by Posthoc Tukey test for comparison between reproductive phases. Level of significance indicate p-value was $0.05 \%$ in LH and progesterone; NS in estradiol and cortical in all phases of menstrual cycle

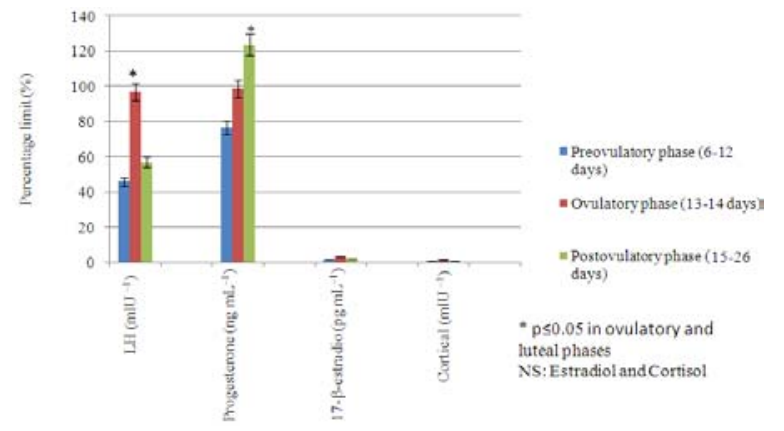

Fig. 2: The salivary hormone during menstrual cycle analyzed during electrolytes assessment in women. *: To be used as a guide only. Each laboratory should establish its own range

Conjugated steroids enter saliva via "ultra filtration" through the tight junctions between the acinar cells and their concentration in saliva is highly flow-rate dependent. Values of salivary Luteinizing hormone level was markedly increased ( $\mathrm{F}=2.786 ; 96.54 \pm 28.65$, $\mathrm{p} \leq 0.05$ ) in ovulatory phase as compared to other phases, whereas the cortical and estradiol concentration was not significantly different at in all phases. The values of progesterone were varied from reproductive phases $76.4-123.7 \mathrm{ng} \mathrm{mL}^{-1}$. The salivary progesterone was raise in postovulatory phase $(\mathrm{F}=3.243$; $123.7 \pm 56.98 \mathrm{p} \leq 0.05)$ showed highly significant which indicates the period of fertility provide evidence the successive rate is $100 \%$ (Fig. 2). Electrolytes like sodium and potassium were drastically high which imply with the salivary hormone are correlated as $98 \%$ of $\mathrm{LH}$ forms a spike during the time of ovulation. Linear plot curve represents in salivary LH was correlated in ovulatory phase as $\mathrm{y}=5.555 \mathrm{x}+55.29 ; \mathrm{R}^{2}=$ 0.043 . Progesterone indicate the plot value as $23.65 \mathrm{x}+52.26 ; \mathrm{R}^{2}=0.998$ has good correlation in postovulatory phase than in other phases which indicates the ovulation percentile rate was $100 \%$ for prognosis in women (Fig. 3). It confirmed that the salivary hormone has good correlation along with electrolytes proves as a marker for ovulation prediction through noninvasive approach. This is also influences on salivary ferning that proves these salts mimics with

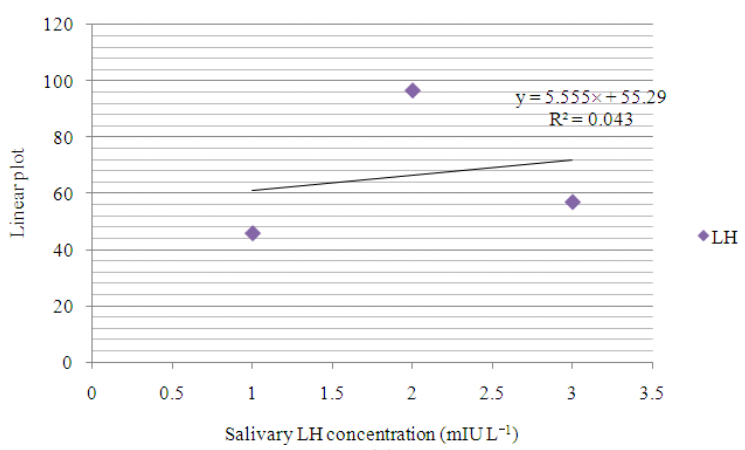

(a)

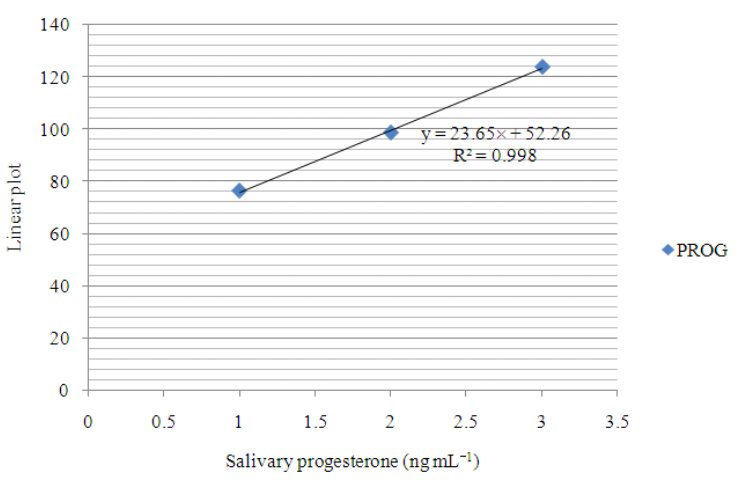

(b)

Fig. 3: Linear plot curve for Salivary LH and Progesterone during menstrual cycle (a) LH; (b) Progesterone in saliva followed by EIA

hormone to form ferning which bring out the day of fertile period in women prospectively (Pattanasuttinont et al., 2007). The coefficient variation in salivary hormone levels was wide-ranging from 0.857-1.81 in all phases of menstrual cycle. Conversely, the concentration of conjugated steroids and protein hormones in saliva probably does not reflect their concentration in plasma in any clinically useful way.

\section{DISCUSSION}

The cyclic hormonal changes can affect a variety of physiological and biochemical processes. There are very few reports on the changes in serum calcium, 
magnesium and inorganic phosphorus levels in various phases of the menstrual cycle in or else healthy women. The present investigation revealed that salivary electrolyte considerably varied depending upon the reproductive status of women. During past several years there has been increased interest in the study of relationship between the essential minerals and ovarian hormones activity. Although the coordinated sequence of hormonal changes during the normal menstrual cycle is well characterized, whether similar or parallel changes occur in the distribution of selected minerals have not been clearly established. Several studies have provided evidence for phase related changes in blood and salivary constituents during menstrual cycle (Dadlani et al., 1982; Pitkin et al., 1978; Patricia, 1987). Further, the current study revealed distinct changes occur in blood calcium, magnesium, potassium, sodium (Marder et al., 1972) and inorganic phosphate (Ben-Aryeh et al., 1976; Voda et al., 1980). Gradual but significant increase in salivary sodium level was seen during ovulatory and preovulatory phases compared to postovulatory phase. The fact that the change in plasma sodium is not associated with changes in weight or in concentration of urea, creatinine or albumin suggests that total body water and intravascular volume remain constant. Thus it appears that sodium is lost in excess of water in the period of ovulation. The results are analogous to the studies that report serum calcium is in highest concentration during ovulatory phase and in lowest concentration during postovulatory phase (Southam and Gonzaga, 1965) while some have stated slight variation during preovulatory phase though not significant (Carr and Frank, 1957).

In addition to the above regulatory function of phosphorus in the menstrual cycle, the ion appears to be itself regulated by a spectrum of feedback mechanisms and hormone systems. Pitkin et al. (1978) found an associated progressive Parathyroid Hormone (PTH) increase during the follicular phase which peaked at or slightly before LH surged and then fell progressively throughout the luteal phase. Calcium, however, appeared to fall three to four days before ovulation and then increased. The authors explain these changes on the basis of estrogen. That is, as estrogen rises preovulatory, $\mathrm{PTH}$-induced hypocalcemia induces $\mathrm{PTH}$ secretion resulting in phosphoturia (Pitkin et al., 1978). One can logically conclude that continuous phosphorus loss should be reflected in lowered serum concentrations unless counteracted by some other mechanism. Since the data obtained in this study indicates that serum phosphorus remains within normal limits, it is possible that the salivary gland or perhaps some other regulator may perform the function of maintaining normal serum phosphorus concentrations across the menstrual cycle.

Changes in progesterone concentrations are not correlated with the changes in plasma sodium during menstruation, suggesting that this hormone does not account for the change between the preovulatory phase and the postovulatory phase. Possible cause for this change in sodium concentration includes the increased concentrations of antidiuretic hormone in the postovulatory phase (Mikkelsen et al., 1965), or of other steroid hormones or metabolites that were not measured in this study. Further, this change in plasma sodium supports the claim of many women that they suffer changes in fluid balance in the premenstrual days. The change in urea, magnesium, calcium, total phosphate and potassium concentration parallels that seen after menopause. During the postovulatory phase the concentration of ovarian steroids in the circulation is high and the urea concentration is low, whereas in the preovulatory phase reverse is true. Again, we saw there was a in electrolytes like sodium and potassium ions were correlated between the concentration of progesterone in saliva during the postovulatory phase. The level of sodium and potassium measured in the women triplicates whose progesterone levels indicated that ovulation took place varied from phase to phase during menstrual cycle.

It is reported that estrogen causes increase in parathyroid activity (Pitkin et al., 1978) which leads to marked acceleration of calcium uptake (Connor et al., 1994; Heaney, 1993) and decreases of its elimination from pigeon's gut (Silberberg and Silberberg, 1956). Increments in blood calcium can result in increased bone density in healthy women (Rocker, 1993). From result, it is evident that estrogen alone possibly caused increase in blood calcium level during preovulatory and ovulatory phases through parathyroid hormone regulation withdrawal of estrogen causes significant decrease less of bone calcium (Christiansen et al., 1987).

Increased serum calcium levels during the ovulatory phase may also contribute to the decreased magnesium levels by exerting an effect on the cell permeability. It is well known that low magnesium levels result in the constriction of cerebral and abdominal blood vessels. It is, thus, also possible that the water retention (bloating) that occurs during the postovulatory phase results, in part, from a slight increase in the constriction of the renal arterial vessels (Pandya et al., 1995). Although estrogen increased during post ovulatory phase. Calcium level was found to be low. This cannot be explained on the basis of 
estrogen levels and parathyroid activity alone; probably progesterone might have had more influence on it. Higher level of progesterone than estrogen during postovulatory phase may interfere the activity of estrogen. Alternatively, because of priming effect of estrogen is utilized to enhance the progesterone activity and may not involve in calcium uptake during postovulatory phase.

There is controversy regarding serum magnesium concentration during menstrual cycle (Pitkin et al., 1978). Our study shows salivary magnesium level is highest during ovulatory and preovulatory and which is least at postovulatory periods. Ovulatory period shows on salivary magnesium may be related to preovulatory estrogen peak (Goldsmith et al., 1970). It could be related to concurrent luteinizing hormone and follicle stimulating hormone peaks but gonadotropin effect on mineral retention probably requires on active gonad (Johnson et al., 1970).

Changes in plasma magnesium level could also be related to changes in basal metabolism rate-BMR (Solomon et al., 1982). Increase BMR and oxygen consumption during preovulatory phase is associated with increased carbohydrate utilization. This carbohydrate utilization requires magnesium ion and oxidative enzymes which was found to be increased significantly during postovulatory phase (Czaja, 1978; Das and Jana, 1991). Serum magnesium concentration has been possibly correlated with Basal Body Temperature (BBT) during ovulation and the postovulatory phase half cycle but whether magnesium increase is a cause or effect of increased heat content is difficult to decide. Although the hormone levels were not measured during this study, it seems likely that progesterone is responsible for rise in both BBT and serum magnesium, which increased in parallel in a single day 7, (Das and Jana, 1991). A comparison of the ovulatory electrolyte concentrations with those of the other designated points in the menstrual cycle showed a decrease in magnesium concentration and a decrease in flow rate at ovulation. These changes in the menstrual cycle maybe due to hormonal changes in the cycle (most likely estrogen).

\section{CONCLUSION}

This study make possible us to quantify the salivary electrolytes like sodium, potassium calcium, magnesium and phosphorus levels in females for the detection of ovulation. The increase of activity tended to coincide with the increase in salivary hormones like LH and progesterone level shows $100 \%$ spike in linear plot which proves the day of ovulation. Further, making more attempts of the measured compounds proved to be a reliable marker for ovulation. Since as a clinico chemical point of view, the remarkable cyclic variation is important to know because whole saliva is frequently used as a diagnostic aid in the management of fertility.

\section{REFERENCES}

Alagendran, S., C. Anchana Devi, K. Karthikeyan, N. Arulmozhi and N. Pushpa, 2009. Evaluation of thyroid profile in human saliva with special reference to ovulation. Res. J. Med. Med. Sci., 4: 441-445. http://insipub.net/rjmms/2009/441445.pdf

Alagendran, S., G. Archunan and S. Achiraman, 2007. Prediction of ovulation in women through the occurrence of salivary fern prototype. ICFAI J. Life Sci., 1: 7-15.

Baron, D.N. and J.L. Bell, 1959. Compleximetric determination of calcium in pathological and physiological specimens. J. Clin. Pathol., 12: 143-148. PMCID: PMC479878

Ben-Aryeh, H., S. Faldir, D. Gutman, R. Szargel and E. Paldi, 1976. Salivary phosphate as an indicator of ovulation. Am. J. Obstet. Gynecol., 125: 871-874. PMID: 937416

Carr, M.H. and H.A. Frank, 1957. Normal serum electrolytes with a note on seasonal and menstrual variation. J. Lab. Clin. Med., 49: 246-252. PMID: 13398689

Christiansen, C., B.J. Riss and P. Rodro, 1987. Prediction of rapid bone loss in postmensopausal women. Lancet, 1: 1105-1108. PMID: 2883442

Connor, E.M., R.S. Sperling, R. Gelber, P. Kiselev and G. Scott et al., 1994. Reduction of maternal-infant transmission of human immunodeficiency virus type 1 with zidovudine treatment. Pediatric AIDS Clinical Trials Group Protocol 076 Study Group. N. Engl. J. Med., 331: 1173-1180. PMID: 7935654

Czaja, J.A., 1978. Ovarian influences on primate food intake: Assessment of progesterone actions. Physiol. Behav., 21: 923-928. DOI: 10.1016/00319384(78)90167-1

Dadlani, A.G., S. Chandwani, C.A. Desai and K.D. Pandya, 1982. Serum electrolytes during various phases of menstrual cycle. Indian J. Physiol. Pharmacol., 26: 302-306.

Das, T.K. and H. Jana, 1991. Basal oxygen consumption during different phases of menstrual cycle. Ind. J. Med. Res., 94: 16-19. http://cat.inist.fr/?aModele $=$ afficheN\&cpsidt $=5238$ 898 
Dorn, L.D., J.F. Lucke, T.L. Loucks and S.L. Berga, 2007. Salivary cortical reflects serum cortical: Analysis of circadian profiles. Ann. Clin. Biochem., 44: 281-284. DOI: 10.1258/000456307780480954

Goldsmith, N.F., N. Pace, J.P. Bammberger and H. Ury, 1970. Magnesium and citrate during menstrual cycle, effect of oral contraceptive on serum magnesium. Fert. Steril., 2: 292-300.

Gowenlock, A.H., 1988. Varley's Practical Clinical Biochemistry. 6th Edn., CRC Press, Boca Raton, FL., ISBN: 13: 9780849301568 , pp: 1050.

Heaney, R.P., 1993. Thinking straight about calcium. N. Engl. J. Med., 328: 503-505. DOI: 10.1056/NEJM199302183280710

Hofman, L.F., 2001. Human saliva as a diagnostic specimen. J. Nutr., 131: 1621S-1625S. PMID: 11340128

Johnson, A.J., J.O. James, J.S. Baumber and E.G. Schneider, 1970. Effect of estrogen and progesterone on electrolyte balance in normal dog. Am. J. Physiol., 219: 1691-1697. PMID: 5485687

Landau, R.L. and K. Lugibihl, 1958. Inhibition of the sodium-retaining influence of aldosterone by progesterone. J. Clin. Endocrinol. Metab., 18: 1237-1245. DOI: 10.1210/jcem-18-11-1237

Lipson, S.F. and P.T. Ellison, 1996. Comparison of salivary steroid profiles in naturally occurring conception and non-conception cycles. Hum. Reprod., 11: 2090-2096. PMID: 8943508

Loewit, K., J. Huber, A. Ortlieb, H.G. Kraft and R. Widhalm et al., 1987. Salivary LH as an ovulation indicator: Comparison between salivary LH, serum LH and ultrasonic findings. Geburtshilfe Frauenheilkd, 47: 800-802.

Marder, M.Z., S. Wotman and I.D. Mandel, 1972. Salivary electrolyte changes during pregnancy. I. Normal pregnancy. Am. J. Obstet. Gynecol., 112: $233-236$.

Mikkelsen, W.M., H.J. Dodge, H. Valkenburg and S. Himes, 1965. The distribution of serum uric acid values in a population unselected as to gout and hyperuricaemia. Am. J. Med., 39: 242-251. http://www.amjmed.com/article/00029343(65)90048-3/abstract\#article-footnote-1

Navazesh, M., 1993. Methods for collecting saliva. Ann. N. Y. Acad. Sci., 694: 72-77. DOI: 10.1111/j.1749-6632.1993.tb18343.x

Neill, D.W. and R.A. Neely, 1956. The estimation of magnesium in serum using titan yellow. J. Clin. Pathol., 9: 162-163. DOI: 10.1136/jcp.9.2.162

Oster, G. and S.L. Yang, 1972. Cyclic variation of sialic acid content in saliva. Am. J. Obstet. Gynecol., 114: 190-193. PMID: 4635756
Pandya, A.K., S. Chandwani, T.K. Das and K.D. Pandya, 1995. Serum calcium, magnesium and inorganic phosphorous levels during various phases of menstrual cycle. Ind. J. Physiol. Pharmacol., 39: 411-414. http://imsear.hellis.org/handle/123456789/108129

Patricia, A.D., 1987. Magnesium and zinc status during menstrual cycle. Am. J. Obstet. Gynecol., 157: 964-968.

Pitkin, R.M., W.A. Reynolds, G.A. Williams and G.K. Hargis, 1978. Calcium-regulating hormones during the menstrual cycle. J. Clin. Endocrinol. Metab., 47: 626-632. DOI: 10.1210/jcem-47-3-626

Rocker, L., 1993. Influence of physical exertion on the hemostasis system. Assessment with sensitive biochemical markers. Dutsch. Med. Wochenschr., 118: 348-354.

Shirtcliff, E.A., D.A., Granger, E. Schwartz and M.J. Curran, 2001. Use of salivary biomarkers in biobehavioral research: Cotton-based sample collection methods can interfere with salivary immunoassay results. Psychoneuroendocrinology, 26: $165-173$.

Silberberg, M. and R. Silberberg, 1956. Steroid Hormones and Bone. In: Biochemistry and Physiology of Bone, Bourne, G.H. (Ed.). Academic Press, New York, ISBN: 10: 0121192040, pp: 632-644.

Solomon, S.J., M.S. Kurer and D.H. Calloway, 1982. Menstrual cycle and basal metabolic rate in women. Am. J. Clin. Nutr., 36: 611-616. http://www.ajcn.org/cgi/content/abstract/36/4/611

Southam, A.L. and F.P. Gonzaga, 1965. Systemic changes during the menstrual cycle. Am. J. Obstet. Gynecol., 91: 142-165.

Vining, R.F. and R.A. McGinley, 1987. The measurement of hormones in saliva: Possibilities and pitfalls. J. Steroid Biochem., 27: 81-94. DOI: 10.1016/0022-4731(87)90297-4

Voda, A.M., K. Wilde and B.P. Gill, 1980. Serum phosphorus during the menstrual cycle. Contraception, 22: 63-69. PMID: 7418408

Pattanasuttinont, S., W. Sereepapong and S. Suwajanakorn, 2007. The salivary ferning test and ovulation in clomiphene citrate-stimulated cycles. Med. Assoc. Thai., 90: 876-883. PMID: 17596040 